\title{
Reform and Practice of Innovative Teaching in Investment Courses Based on Three-dimensional Bidirectional Network
}

\author{
Chi-Chuan LEE *, and Ruyu Zhang \\ School of Management, Beijing Normal University Zhuhai, Zhuhai 519087, China; \\ * Corresponding author
}

\begin{abstract}
Keywords: Investment; Teaching Reform; Multimedia; Heuristic Teaching; Experiential Learning
\end{abstract}
\begin{abstract}
Investment course teaching reform aims to cultivate students' autonomous learning ability, practical ability, and innovative ability. The key to achieving the above goal is to guide students to change their learning behavior. Combined with the development of modern information technology and the practical needs of curriculum teaching and based on the existing curriculum and teaching organization, this study optimizes and perfects the overall design, and establishes a new mode of integrated and coordinated feedback teaching from network multimedia teaching, interesting heuristic teaching, and virtual simulation teaching. The results of the study will help to fully stimulate students' interest and initiative in learning and cultivate comprehensive talents meeting the needs of modern society.
\end{abstract}

\section{Introduction}

Investment is a comprehensive course to study investment activities and their laws. The investment course is based on the general problems encountered in the process of investment and supported by the basic theories of modern finance. It helps to enable students to systematically understand and master the basic knowledge and skills of investment, including the understanding of the investment process and environment, the theories of efficient market, capital asset pricing, bond and futures option pricing, and the methods of investment decision-making. It also cultivates students' intuition and general thinking to deal with real investment problems. However, the characteristics of this course have caused great difficulties to the teaching of investment. On the one hand, it is difficult for students to understand the theoretical model in depth. On the other hand, the classroom teaching lacks the practice of real participation in the market, which cannot be applied to the study, thus affecting the quality of personnel training in the field of finance and economics. [1] The causes of these phenomena and results deserve deep consideration and study, forcing us to carry out reforms in teaching concepts and methods, so as to achieve the desired objectives of teaching reform in investment.

Most scholars believe that the current investment in education cannot achieve the desired teaching objectives, because the traditional teaching environment is teacher-centered, book-based static teaching model [2]. Students can only be taught by teachers to absorb knowledge, during which not only the interaction between teachers and students is less, but also the initiative of students cannot be stimulated. Moreover, the content of investment involves many difficult mathematical operations and theoretical models, which not only unable to stimulate students' interest in learning, but also make students feel frustrated in learning, ultimately leading to unsatisfactory learning results.

With the rapid development of computer network and information technology, the traditional teaching and learning methods have been greatly impacted and transformed [3,4]. The change of teaching environment determines the change of teaching materials and teaching methods. The knowledge that can only be obtained from textbooks and classrooms can now be easily obtained through the Internet. In addition, multimedia technology has been widely applied in the field of education, $[5,6,7]$. Teachers can easily integrate the relevant information of the course into the content of the textbook through multimedia technology, so as to enrich their own textbooks. And students can also carry out assisted learning on the network, so that learning activities can be more autonomous and lively. As the medium of teaching, network and information technology have opened up a new way to improve the teaching effect and achieve the purpose of teaching and learning. 
Based on the current teaching situation and existing problems of practical teaching in investment courses, as well as the development of modern science and technology and the popularization of multimedia, this research will put forward a comprehensive reform idea in teaching means and methods, teaching forms and contents, teaching organization and control. This teaching reform achieves the predetermined teaching objectives through the three-dimensional teaching model. We extend the traditional "one-dimensional and one-way" static teaching mode to the new "three-dimensional and two-way" feedback teaching mode, which integrates and coordinates the network multimedia teaching, interesting heuristic teaching, and virtual simulation teaching.

\section{Main Problems in Current Investment Teaching}

\subsection{Single teaching methods and ways}

At present, the teaching form of investment courses in China is relatively fixed. The teaching methods are also relatively simple. For a long time, the teaching method which mainly focuses on classroom teaching is still essentially a continuation of the previous "cramming" teaching mode of theoretical courses. Under this situation, although students passively fulfill their learning objectives according to established teaching objectives, students tend to feel bored easily. In addition, the classroom atmosphere is too rigid to stimulate students' curiosity. Therefore, students attend class inefficiently and teachers cannot achieve the desired effect.

\subsection{Attach importance to theory and despise practice}

At present, investment teaching in most universities is mainly based on classical investment theory, and teachers often only pay attention to the understanding and extension of theoretical knowledge, and focus on the analysis and validation of investment theory in the process of teaching. However, the update speed of teaching content lags behind the development of investment practice, ignoring the cultivation of college students' practical ability [8], which deviates from the training direction and training objectives of investment practice.

\subsection{Weak practice teaching}

Practical teaching is an effective way to consolidate theoretical knowledge and deepen theoretical understanding. It is also an important link in training innovative talents. At present, the construction of financial laboratories in many colleges and universities in China is relatively backward, lacking the software and hardware equipment for analog transaction and analysis. At the same time, due to the lack of experimental teaching teachers, teaching is still stuck in the classroom teaching. In this regard, the experimental operation, simulation transactions, case teaching, and practical teaching are seriously inadequate.

\section{Thinking of Teaching Reform of Investment Based on Three-dimensional Teaching System}

The core content of this study is to reform the teaching mode of investment course. To cultivate students' autonomous learning ability, practical ability, and innovative ability, we break through the traditional single classroom teaching by adopting various teaching resources. It covers the knowledge and content of the teaching process from various angles, and therefore formulating and implementing a set of relatively perfect and adapt to the new era of investment course teaching mode as shown in Fig. 1. 


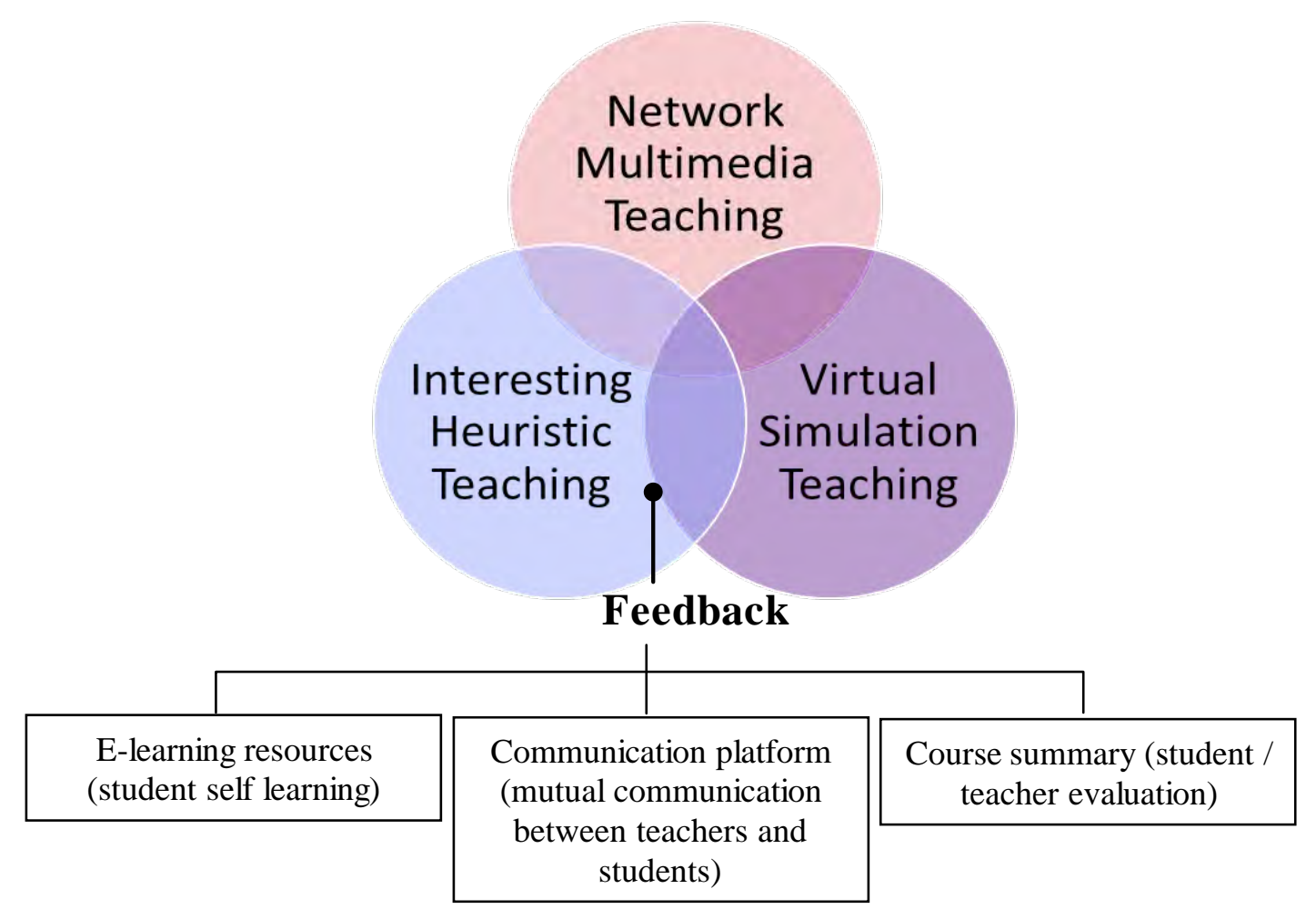

Fig. 1 New mode of three-dimensional two-way feedback teaching

\subsection{Network multimedia interactive teaching - making good use of new media teaching}

Given the time and space constraints, the traditional classroom teaching methods only transmit information means of words and simple images. Besides, the current textbooks are mostly in the form of the written arrangement and lack of relevant audio-visual aided learning materials. Students are easily bored and unable to concentrate in class, making the process of knowledge transmission often interrupted or incomplete. The application of multimedia technology to teaching practice is an important direction of teaching reform. Media in multimedia technology is the carrier of information transmission. The use of media to convey teaching information is an important symbol of teaching concepts and teaching methods. The media which presents teaching information with sound, animation, picture, color, and the image has the characteristics of capacity, availability, vividness, availability, repeatability. The advantage of using multimedia interactive teaching to transmit teaching information lies in its refined and complete form, which shows rich expressiveness and appeal of the relevant theories and skills in teaching. This course uses multimedia to extract the unit themes of each course. Through 1-3 minutes of multimedia textbooks before class, we decompose the important knowledge points of investment courses. In class, with students as the main body, we carry out 10-15 minutes of discussion and explanation and highlight the viewpoints and phenomena involved in the teaching content. By doing so, we break through the difficult points, repeatedly provide clear and continuous guidance for students' learning process, and establishes students' profound logical thinking.

\subsection{Interesting heuristic teaching -innovating traditional teaching}

In the teaching mode of traditional investment courses, teachers can only use textbooks as the main line in the classroom, explaining the basic theory and supplementing with a few cases. However, many concepts of modern finance and investment are more abstract. Simply teaching the content from the text without the actual operation and exercise will make it difficult for students to grasp many abstract problems. Therefore, interesting heuristic teaching can make up for the shortcomings of classroom teaching. The concept of financial games and financial education has been widely studied and promoted abroad. Using improved investment and wealth management games, students are capable of making investment decisions through individuals and groups. By continuously practicing, students can not only gain investment and financial management knowledge from natural learning, but also enhance learning fun without psychological burden, and thus improve learning outcomes. In the process of student participation, the game explanations and 
meanings are added for each type, and the conceptual abstraction theory and practice methods of "learning by doing" and "doing by learning" can be understood. Moreover, through the guidance of the teacher and the progress of the game, the students can discuss each other and make financial decisions positively rather than passively. This will be conducive to students to deepen their understanding of theoretical knowledge in the process of learning, to cultivate independent ability to think, analyze and solve problems and improve classroom teaching effect greatly while stimulating students' interest in learning.

\subsection{Virtual simulation teaching — strengthening skill teaching}

Classroom teaching is dominated by teachers and students are the main body. If we merely explain the theory and operation of securities, and there is no interaction between the leader and the subject, then the course teaching will be boring, and the knowledge that students can absorb will not be able to improve the skills and the quality. Educational psychology points out that the learning process is not only a process of knowledge transfer, but also a complex psychological process including emotional processes and will. Emotional factors play an important role in the teaching process. Therefore, this course introduces the concept of experiential learning and proposes that effective learning should start from the experience, and then express opinions on the actual problems encountered in the experience process, reflect on it, then summarize the theory, and finally apply the theory to practice. In this process, emphasis is placed on the sharing and application of knowledge. For example, using the competition model of securities investment simulation trading, students conduct a simulated trading contest in a group mode. The teacher announces the group's game status before the class every week and invites the three groups with the highest and worst earnings to report on the investment strategy. During the competition, students can use various market analysis systems to dynamically observe securities and analyze, judge them in combination with classroom teaching content, conduct actual verification on the main content of the investment course to achieve an effective combination of theory and practice, strengthen students' self-learning ability, form a teamwork atmosphere, and improve the practicality of the course. The virtual simulation teaching has the characteristics of active learning, containing education in amusement, learning to use, and combining virtual and real, so that the theoretical and conceptual knowledge in the classroom becomes a practical and operable procedure. This kind of specific experiential learning mode is to conduct securities investment simulation, market analysis and investment strategy test through experimental means, so that students can deeply understand and master the relevant investment theory knowledge and practical application. At the same time, through the experimental operation, the initiative of students' cognition is greatly mobilized, and students' comprehensive knowledge application ability, practical ability and decision-making ability are cultivated to further meet the needs of high-level innovative talents in economic and social development.

\section{Conclusion}

As a core course of economics and management in colleges and universities, investment science has a strong theoretical, professional and practical. Traditional teaching methods cannot effectively stimulate students' interest in learning, and students' learning effects are not ideal. It is difficult to cultivate comprehensive talents that meet the needs of modern society. In the teaching process, students are the main body of learning, and teachers play the role of organizers, leaders, helpers, and promoters. Through diversified three-dimensional teaching methods, this research takes teachers as the leading factor and students as the main body and makes use of network multimedia teaching, interesting heuristic teaching and virtual simulation teaching to integrate and coordinate. Using the theory and practice parallel three-dimensional two-way feedback teaching model to strategically induce learning, make the investment course in learning more exciting and lively, thereby improving learning motivation. Through applying mufti-interactive teaching methods and teaching design, students have a sense of participation and can take the initiative to collect and analyze a variety of information. Students can further improve the effectiveness of learning, and become innovative talents to adapt to society. 


\section{Acknowledgment}

This article was funded by the 2017 Teaching Reform and Construction Project from Beijing Normal University Zhuhai Campus "Innovation Teaching Reform and Practice Based on Three-Dimensional Two-Way Investment Course" and the 2017 Teaching Reform and Construction Project from Department of Education of Guangdong Province "Design and Construction of Flipping Classes in the Ubiquitous Learning Context--Based on the Teaching Practice of Asset Evaluation Course. Thanks for funding.

\section{References}

[1]. B. Song, and M. Lin, The Application of Virtual Simulation Technology in the Teaching of Investment the Perspective of Flipping Classrooms, Education Modernization, (10), pp.139-140, 2018.

[2]. C. Wu, Analysis on the Reform of the Teaching Mode of "Investment" Course Based on "Experiential Learning", Contemporary Economics, (21), pp.104-106, 2014.

[3]. B. K. Chiu, K. Solez, and C. M. Sergi, Digital pathology for e-learning and digital education - a review, Journal of Information Technology and Application in Education, 3(4), pp.164-168, 2014.

[4]. H. A. Yamani, E-learning in Saudi Arabia,” Journal of Information Technology and Application in Education, 3(4), pp.169-172, 2014.

[5]. B. Song, and M. Lin, Examining the pedagogical foundations of modern educational computer games, Computers \& Education, (51), pp.1729-1743, 2008.

[6]. M. Robertson, A. Fluck, and I. Webb, Seven Steps to Success with ICTs: Whole School Approaches to Sustainable Change, 1st ed., Camberwell: ACER Press, 2007.

[7]. Y. Hu, and A. Bodomo, Are the most interactive learners on web-based learning systems the best output performers, Journal of Information Technology and Application in Education, 4, pp.8-17, 2015.

[8]. Q. Liu, The Application of Simulation Teaching Method in the Course of Securities Investment, Education Modernization, (37), pp.186-187, 2016. 